\title{
Late Quaternary paleoclimatic and geomorphological evolution at the interface between the Menyuan basin and the Qilian Mountains, northeastern Tibetan Plateau
}

\author{
Xianyan Wang a,b,*, Dimitri Vandenberghe ${ }^{c}$, Shuangwen Yi ${ }^{\text {a }}$, Jef Vandenberghe ${ }^{\text {a,b }}$, Huayu Lu ${ }^{\text {a }}$, \\ Ronald Van Balen ${ }^{\mathrm{b}}$, Peter Van den Haute ${ }^{\mathrm{c}}$ \\ a School of Geographic and Oceanographic Sciences, MOE Key Laboratory of Coast and Island Development, Nanjing University, Nanjing 210093, China \\ b Institute of Earth Sciences, VU University Amsterdam, De Boelelaan 1085, 1081 HV Amsterdam, The Netherlands \\ c Department of Geology and Soil Science, Laboratory of Mineralogy and Petrology (Luminescence Research Group), Ghent University, Krijgslaan 281 (S8), B-9000 Gent, Belgium
}

\section{A R T I C L E I N F O}

\section{Article history:}

Received 28 December 2012

Available online 11 October 2013

\section{Keywords:}

LGM

Cryoturbation

Paleoclimate

Fluvial aggradation

OSL dating

Northeastern Tibetan Plateau

\begin{abstract}
A B S T R A C T
The Tibetan Plateau is regarded as an amplifier and driver of environmental change in adjacent regions because of its extent and high altitude. However, reliable age control for paleoenvironmental information on the plateau is limited. OSL appears to be a valid method to constrain the age of deposits of glacial and fluvial origin, soils and periglacial structures in the Menyuan basin on the northeastern Tibetan Plateau. Dating results show glaciers advanced extensively to the foot of the Qilian mountains at $\sim 21 \mathrm{ka}$, in agreement with the timing of the global Last Glacial Maximum (LGM) recorded in Northern Hemisphere ice cores. Comparison with results from the eastern Tibetan Plateau suggests that the factor controlling glacial advance in both regions was decreased temperature, not monsoon-related precipitation increase. The areas of the Menyuan basin occupied by glacio-fluvial deposits experienced continuous permafrost during the LGM, indicated by large cryoturbation features, interpreted to indicate that the mean annual temperature was $\geq 7{ }^{\circ} \mathrm{C}$ lower than at present. Glacio-fluvial systems in the Menyuan basin aggraded and terraces formed during cold periods (penultimate glaciation, LGM, and possibly the Younger Dryas) as a response to increased glacial sediment production and meltwater runoff then.
\end{abstract}

(C) 2013 University of Washington. Published by Elsevier Inc. All rights reserved.

\section{Introduction}

The Tibetan Plateau is thought to be a critical factor in the environmental evolution in Asia, especially as an amplifier and driver of climatic change due to its high altitude over a vast area (e.g. Pan et al., 1995; Liu and Chen, 2000). However, paleoenvironmental conditions (especially air temperature) and landscape evolution interlinked with climate change there are not clearly understood. This is due to insufficient paleoenvironmental indicators and reliable age control, especially in the northeastern part of the region.

Glacier fluctuations (e.g. Derbyshire, 1987; Shi, 2002; Zhou et al., 2002; Yi et al., 2008; Owen, 2009) and periglacial structures (formed by thaw modification of frozen ground; e.g. Porter et al., 2001; Wang et al., 2003; Vandenberghe et al., 2004; Liu et al., 2013) have been used to reconstruct former paleoenvironmental conditions in the study region and its surrounding areas. However, there is an ongoing debate on the timing of Quaternary glaciations and their relationship

\footnotetext{
* Corresponding author at: School of Geographic and Oceanographic Sciences, MOE Key Laboratory of Coast and Island Development, Nanjing University, Nanjing 210093, China. Fax: + 862583686740 .

E-mail addresses: xianyanwang@nju.edu.cn (X. Wang), jef.vandenberghe@falw.vu.nl (J. Vandenberghe)
}

to changes of precipitation and temperature (e.g. Shi, 2002; Zhou et al., 2002; Lehmkuhl and Owen, 2005; Owen et al., 2009; Zhou et al., 2010; Ou et al., 2012), which is partly due to a lack of suitable datable materials (for radiocarbon and terrestrial cosmogenic nuclides exposure-age dating). Although the timing and succession of glaciations are ill-defined as a consequence of poor chronological control in most parts of the Tibetan Plateau, it was previously concluded that glacial advances there were mainly influenced by precipitation, controlled by the South Asian monsoon (e.g. Owen et al., 2009). However, it was also proposed that in the eastern Tibetan Plateau glacial advances during the last glacial period were mainly controlled by temperature and that the precipitation is a secondary factor (Ou et al., 2012). In addition, it was pointed out that the glacial advances in the southeastern Tibetan Plateau occurred during Marine Oxygen Isotope Stage (MIS) 3 and the early Holocene, while they were scarce during the global Last Glacial Maximum (LGM) (e.g. Owen et al., 2009). Some authors concluded also that in accordance with the glacial advances, rivers aggraded and filled valleys during MIS 3 in the southern Tibetan Plateau (e.g. Goodbred, 2003; Dutta et al., 2012).

In the Qilian Mountains of the northeastern Tibetan Plateau, several glacial advances dating from 470-460 ka have been reported, occurring during the penultimate glaciation, the last glaciation, and the Little Ice Age (Kang et al., 1992; Guo et al., 1995; Zhao et al., 2001; Zhou et al., 
2002). Age constraints in these studies are limited to a few radiocarbon and electron spin resonance (ESR) dates (Kang et al., 1992; Guo et al., 1995; Zhao et al., 2001; Zhou et al., 2002). Likewise, the age control on periglacial conditions is poor. Thus far, aeolian sands in sand wedges have been dated as LGM near Qinghai Lake, in the Hexi Corridor and on the Mu Us desert by using thermoluminescence (TL) and optically stimulated luminescence (OSL), supplemented by a few radiocarbon ages of fluvial and lacustrine deposits (Porter et al., 2001; Wang et al., 2003; Vandenberghe et al., 2004; Liu and Lai, 2013). These results show the presence of continuous permafrost during the LGM, indicating that at that time the mean annual temperatures were more than $\sim 12^{\circ} \mathrm{C}$ lower (Wang et al., 2003; Vandenberghe et al., 2004) or $\sim 3{ }^{\circ} \mathrm{C}$ lower (Porter et al., 2001) than nowadays.

In accordance with the morphological evolution in glacial environments, a few case studies (e.g. Pan et al., 2009) have shown that fluvial aggradation took place during periglacial conditions on the Tibetan Plateau during the Pleistocene, caused by changes in precipitation, cessation of soil development and decrease of vegetation cover as a response to climate deterioration, which is in agreement with general observations (e.g. Vandenberghe, 1995, 2003; Bridgland and Westaway, 2008; Srivastava et al., 2008; Vandenberghe, 2008). In addition, investigations have shown that fluvial landforms in the northeastern Tibetan Plateau were controlled by both climate change and tectonic uplift (Lu et al., 2004; Vandenberghe et al., 2011; Wang et al., 2012). However, a few studies from the southern Tibetan Plateau have reported fluvial accumulation and valley fill, mainly in interstadial conditions (e.g. in MIS 3) and due to enhanced precipitation associated with a strong insolationcontrolled South-Asian monsoon (e.g. Goodbred, 2003; Thiede et al., 2004; Gibling et al., 2005; Dutta et al., 2012).

The study area is located at the foot of the Qilian Mountains in the northeastern Tibetan Plateau, where glacial valleys and moraines, outwash fans, periglacial structures, and fluvial terraces are extensively present and are morphologically connected. Thus, it is an ideal area to unravel the relationship between the glacial and fluvial processes and their detailed response to climate changes. The objective of this study is to refine and extend the paleoclimatic database and to specify reconstruction of landscape evolution using OSL ages in the glacial and fluvial setting of the Menyuan basin (Fig. 1).

\section{Geomorphological setting}

The Menyuan basin is a topographic depression at the northeastern margin of the Tibetan Plateau, bounded by the Daban Mountains to the south and the Qilian Mountains to the northeast (Fig. 1). The subsurface of the basin consists of reddish Neogene fluvio-lacustrine mudstone, siltstone, and sandstone, overlain by Pleistocene deposits. The altitude of the study area is between $2750 \mathrm{~m}$ and $5200 \mathrm{~m}$. The mean annual temperature and precipitation are $\sim 0.8{ }^{\circ} \mathrm{C}$ and $\sim 520 \mathrm{~mm}$ respectively. Precipitation falls mainly in the summer, caused by invasions of the East-Asian and south-Asian monsoons. In winter, the climate of this region is controlled by the Mongolian high-pressure cell. The present snowline is at $4400 \mathrm{~m}$. Modern glaciers cover high mountain areas in the study area and the meltwater from high-altitude snow is an important source of fluvial discharge. The Datong River flows through the basin from northwest to southeast.

The morphology of the southern edge of the Qilian Mountains is characterized by glacial valleys, whereas moraines and outwash fans occur just below the mountains in the Menyuan basin. Tributaries to the Datong River have terraces. The fans and terraces are connected to or correlatable to the fluvial terraces of the Datong River in the basin (Fig. 1).

\section{Methods}

Field work

Large-scale landforms were mapped using remotely sensed data from various sources. The principal dataset was the Advanced Spaceborne Thermal Emission and Reflection Radiometer (ASTER) Global Digital Elevation Model (ASTER GDEM), with a horizontal resolution of $30 \mathrm{~m}$ (http://gdem.ersdac.jspacesystems.or.jp). Field work was undertaken on the south slope of the Qilian Mountains and in the Menyuan basin. Firstly, detailed studies were carried out in the Datong catchment to determine the Datong terrace sequence and its spatial distribution. Then, typical topographic sections composing glacial valleys at the southern side of the Qilian Mountains and outwash fans and glacial and fluvio-glacial sediments in the Menyuan basin, were

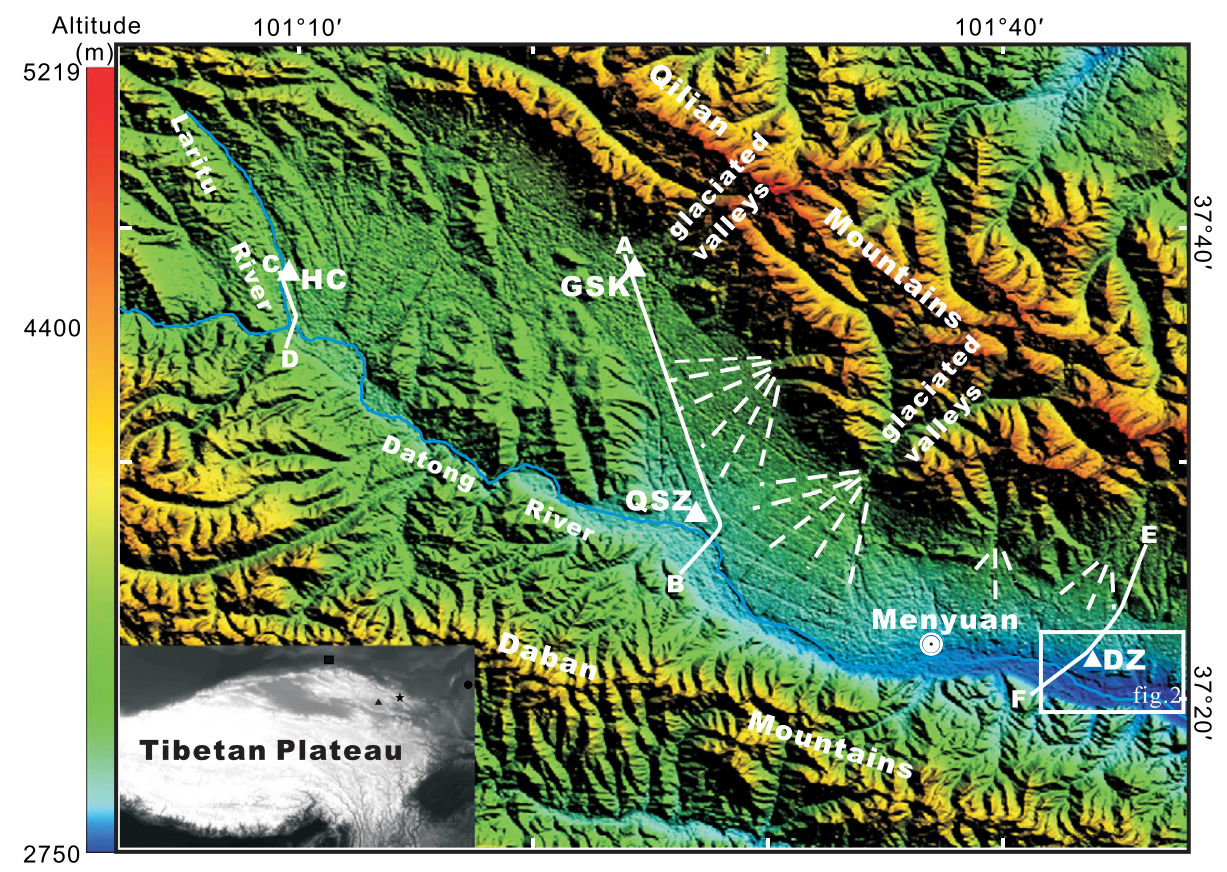

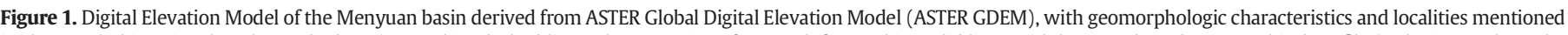

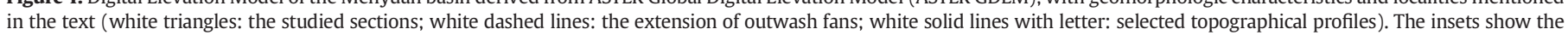
position of the studied region (Menyuan basin) on the Tibetan Plateau (star: Menyuan basin; circle: Mu Us desert; rectangle: Hexi Corridor; triangular: Qinghai Lake). 
morphologically correlated with the terrace sequence of the Datong River. These sections (Gangshika (GSK), Qingshizui (QSZ), Huangcheng (HC), and Dazhuang (DZ); locations in Fig. 1) in combination with topographic analysis in between allowed examination of the relationship between the glacial valleys and moraines in the Qilian Mountains following the outwash fan successions towards the terrace staircase and into the basin.

The individual outcropping deposits were described for their sedimentary structures (using lithofacies according to Miall, 1996; Benn and Owen, 1998), lithological properties, and thickness as far as they could be measured, in order to derive the sedimentary processes. The moraines, outwash fans, and terraces were examined and correlated morpho-stratigraphically, and mapped using a Garmin Vista GPS and Magellan MobileMapper CX, integrated with real-time, sub-meter accuracy using SBAS. For correlation purposes, we used the relative height of the terraces above the present-day floodplain of the Datong River.

\section{Optically stimulated luminescence (OSL) dating}

Sediment samples for OSL dating were collected by hammering light-tight tubes into freshly exposed sediments. The tubes remained sealed until processed in safe light conditions. Within the frame of this work, a total of eleven samples were analyzed. Sample preparation as well as the determination of the dose rate were done at Nanjing University (China); the OSL measurements were undertaken at Ghent University (Belgium) and Nanjing University.

Very fine sand-sized (63-90 $\mu \mathrm{m}$ ) quartz grains were extracted from the inner material of the sampling tubes in the standard manner $(10 \%$ $\mathrm{HCl}, 30 \% \mathrm{H}_{2} \mathrm{O}_{2}$, wet sieving, $40 \% \mathrm{HF}$, and dry sieving). Initial screening suggested that the OSL signals of the samples were not bright and that their luminescence sensitivity was low, similar to other OSL dating studies on the Tibetan Plateau (Lai et al., 2009; Liu et al., 2010; Lu et al., 2011). We therefore analyzed all samples using large aliquots ( $8 \mathrm{~mm}$ diameter). We also analyzed two relatively bright samples (GSK-1 and -2 ) using small aliquots ( 2 mm diameter) and compared the measurement results from small aliquots and large aliquots to assess the degree of partial bleaching, as the glacio-fluvial sediments are likely to suffer from poor or inhomogeneous bleaching. Luminescence measurements were made using automated Risø-readers equipped with blue ( $470 \pm 30 \mathrm{~nm}$ ) LEDs and an IR laser diode $(830 \mathrm{~nm})$. The luminescence emissions were detected through a $7.5 \mathrm{~mm}$ Hoya U-340 UV filter. Details on the measurement apparatus can be found in BøtterJensen et al. (2003).

A single-aliquot regenerative-dose (SAR) protocol (Murray and Wintle, 2000) was used to determine the equivalent dose $\left(D_{e}\right)$. Preheating of natural and regenerative doses was for $10 \mathrm{~s}$ at $240{ }^{\circ} \mathrm{C}$, while the response to the test dose was measured after a cut-heat to $200{ }^{\circ} \mathrm{C}$. Optical stimulation with the blue diodes was for $40 \mathrm{~s}$ at $125^{\circ} \mathrm{C}$. The initial $0.32 \mathrm{~s}$ of the decay curve was used in the calculations, minus a background evaluated from the following $0.64 \mathrm{~s}$. As the samples were not particularly sensitive, a relatively high test dose in the range of $\sim 50-100$ Gy was used for all but sample HC-1; for the latter sample, a test dose of $\sim 6 \mathrm{~Gy}$ was used. After measuring the response to the test dose, a high-temperature bleach was performed by stimulating with the blue diodes for $40 \mathrm{~s}$ at $280{ }^{\circ} \mathrm{C}$ (Murray and Wintle, 2003). For each aliquot, the dose response was obtained by measuring the response to four regenerative doses. This was followed by three additional measurements to obtain estimates of recuperation and recycling (Murray and Wintle, 2000), and purity (OSL IR depletion ratio; Duller, 2003). To assess the reliability of the laboratory measurement procedure, a dose recovery test was performed (Murray and Wintle, 2003). Fresh aliquots were bleached for two times $250 \mathrm{~s}$ using the blue diodes at room temperature; the two bleaching treatments were separated by a $10,000 \mathrm{~s}$ pause. A regenerative dose was then given, chosen to be equal to the estimated natural dose, and measured using the SAR protocol outlined above.

The material from the outer ends of the sampling tubes was retained for radioisotope and water content analysis. The in-situ water content and that at saturation were determined by drying sub-samples in an oven at $50{ }^{\circ} \mathrm{C}$ (Long et al., 2011). A subsample of $\sim 20$ g dried sediment was ground to a fine powder to determine concentrations of $U$, Th, and $\mathrm{K}$ by neutron activation analysis (NAA). The elemental concentrations were converted into external beta and gamma dose rates using the conversion factors of Adamiec and Aitken (1998) and beta attenuation factors of Mejdahl (1979). The water content may have varied over the entire burial period of the samples, but it is difficult to determine the degree of such changes; we have assumed $50 \%$ of the saturation water content as representative for the time-averaged degree of wetness and assigned a relative uncertainty of $25 \%$ to this value to allow for possible fluctuations. An internal dose rate in quartz grains of $0.013 \pm 0.003 \mathrm{~Gy} \mathrm{ka}{ }^{-1}$ was assumed (based on Vandenberghe et al., 2008), and the contribution from cosmic rays was calculated following Prescott and Hutton (1994).

\section{Results}

Firstly, the terrace sequence in the basin is summarized as derived from the DEM analysis and field investigations. Then, three typical sedimentary sections of different ages are described and morphologically correlated with the Datong terrace sequence. Finally, the sedimentological interpretations and the OSL dating results are reported and discussed.

\section{The Datong River terrace staircase in the Menyuan basin}

From the DEM topographic analysis (Fig. 2) and field morphological investigations (Fig. 3a), several extended flat surfaces (or patches) in the Datong valley were distinguished at different altitudes above the present floodplain. Field investigations show that these surfaces are usually underlain by widely occurring fluvial beds, containing gravel from the Datong River, and covered successively by alluvial and aeolian loess (Fig. 3c). In total, six terraces are distinguished (T1 to T6), at around $2 \mathrm{~m}, 7-8 \mathrm{~m}, 13-14 \mathrm{~m}, 21-23 \mathrm{~m}, 43-45 \mathrm{~m}$ and 78-80 $\mathrm{m}$ above the present floodplain level ( $\mathrm{m}$ apf) (Fig. 3c). The different terraces show similar sedimentary properties: fluvial gravels of various thicknesses, interbeded with lenses of sands, silts, and clays and finally topped by a horizontally laminated silt containing gravel strings of limited extent. The gravels consist mainly of quartzite, sandstone, and granite with small amounts of conglomerate and crystalline and metamorphic pebbles, which are mainly rounded to sub-rounded. The lowest part of the gravel deposits consists of massive gravel $(\mathrm{Gm})$ representing channel bedload, grading towards the top into finer-grained, coarsely planar bedding (Gp). The latter deposits frequently show imbrication and small-scale cross-bedding, which indicate lateral and longitudinal bar development during deposition. Small and shallow channels occur with increasing frequency towards the top of the terrace deposits; they are filled with cross-bedded fine gravel or sands (planar to lowangle trough cross-bedding). The gravels are generally matrixsupported, but in the channels they are sometimes clast-supported. The upper laminated silts are floodloam deposits that complete the fluvial sequence prior to or simultaneously with the abandonment of the concerned floodplain as a result of renewed river incision. They may even have been deposited at peak flooding during the initial phase of that renewed river incision.

The three lower terraces (T1, T2, and T3) are widespread along the Datong River and are well expressed in the morphology, whereas the three higher terraces (T4, T5, T6) are distributed as isolated patches. The thickness of the exposed terrace gravel is $2 \mathrm{~m}, 7 \mathrm{~m}, 6-9 \mathrm{~m}, 14 \mathrm{~m}$, $36 \mathrm{~m}$, and 3-5 m for T1, T2, T3, T4, T5 and T6 respectively (Fig. 3c). 


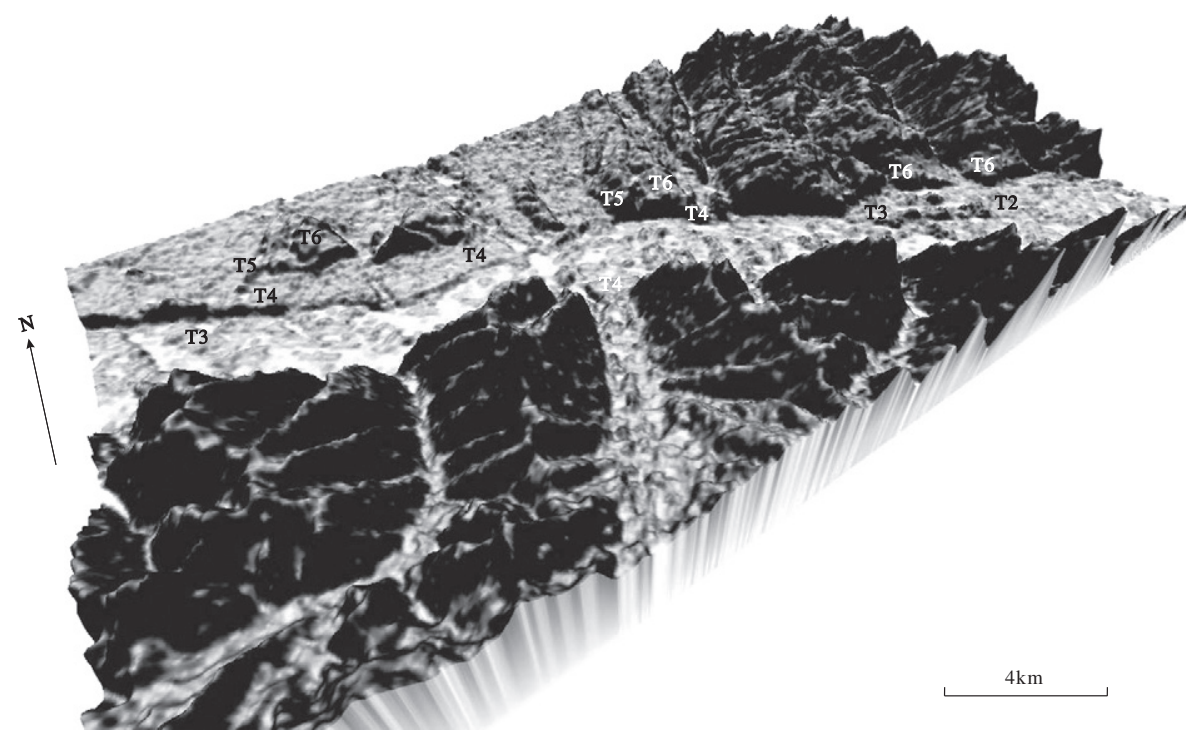

Figure 2. Example 3D-view of a combined slope-elevation map (based on the Aster GDEM) in the eastern part of the Menyuan basin (see the location in Fig. 1), showing terraces T2, T3, T4, T5 and T6, along the Datong valley.

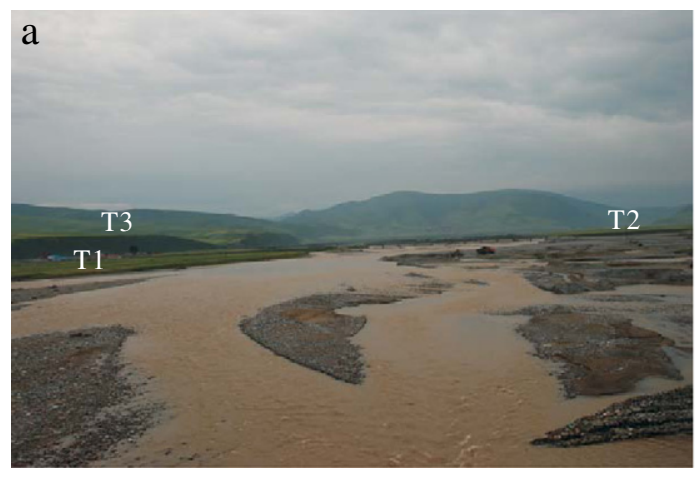

C

000 Gravel
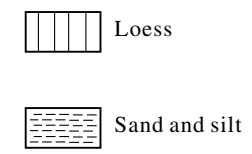

$\mathrm{b}$
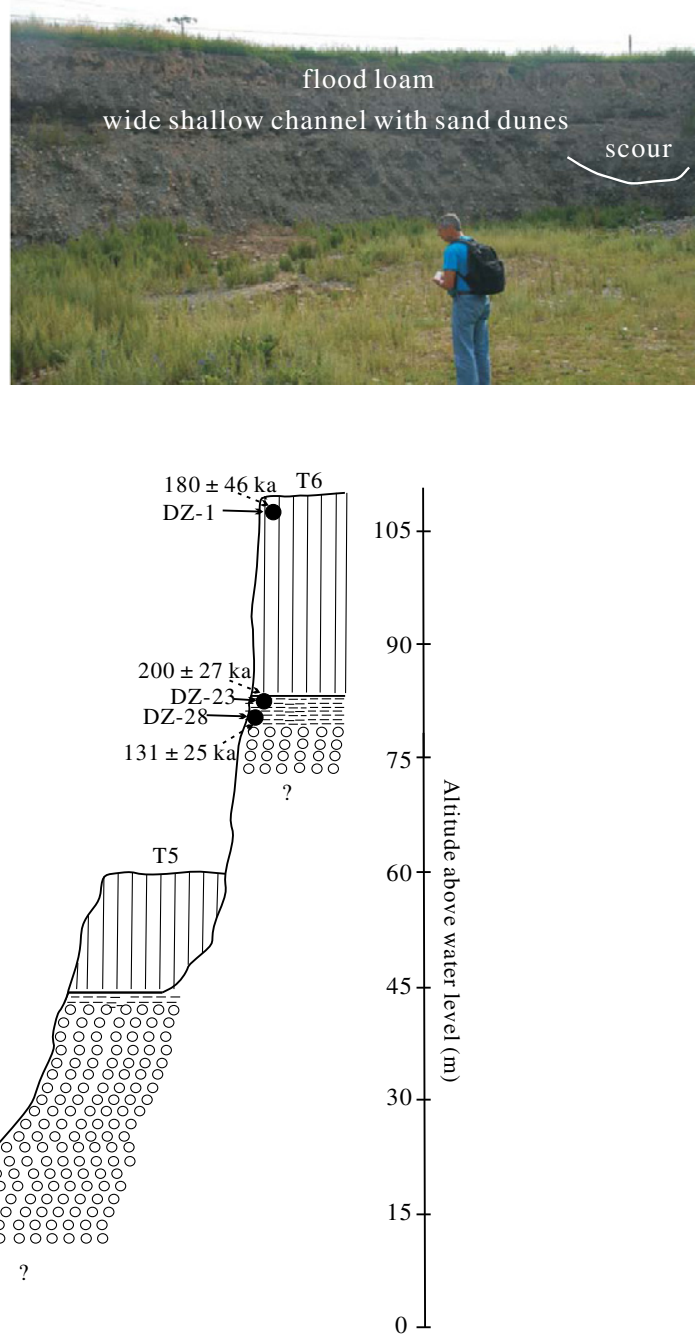

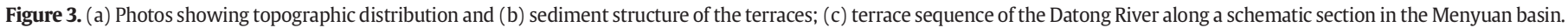


These thicknesses are mostly minima as the base of the gravel deposit is not always exposed. Based on the thicknesses of the gravel deposit, it seems that at least the fifth and fourth terraces (T5 and T4) could be interpreted as accumulation terraces (in this interpretation, we consider that the terrace surface formed due to continuous aggradation of the river). But it is also possible that the complete gravel thickness belongs to the sixth terrace and the later terraces just incised in, and removed part of the former gravel deposit of T6. Additional field data are required to obtain a more detailed insight into the aggradation and incision cyclicity recorded by the higher terrace sequence.

The alluvial loam at the top of the terraces is $0.5-1 \mathrm{~m}$ thick except on the sixth terrace, where it is around $3.2 \mathrm{~m}$. The loess overlying the second (T2), third (T3) and fourth terrace (T4) is 0.5-1.5 m thick. The loess overlying the fifth (T5) and sixth terrace (T6) is around 25-40 m thick. The first terrace is not covered by loess.

In general, the main sediment bodies of these terraces are too coarse-grained for luminescence dating. Two samples (DZ-23 and DZ28) from the flood loam of T6 were taken and one sample (DZ-1) from the top of the overlying loess (DZ section) and one sample (QSZ-1) from the flood loam of T3 at QSZ near the GSK section were taken (Fig. 3c).

\section{Description of the sections and geomorphological correlation}

Three typical sites near the footwall of the Qilian mountain, Gangshika (GSK), Huangcheng (HC) and Dazhuang (DZ) (Fig. 1), were selected for detailed sedimentological description, morphological correlation with the Datong terraces and OSL dating.

1. At the GSK section, a large U-shaped tributary valley, a morainic hillplain and an extensive glacial outwash fan are present (Figs. 1, 4). The top of the studied sedimentary sequence is at around $50 \mathrm{~m}$ above the present floodplain of the Baishui River, and this surface gradually declines to connect with the T5 terrace (43-45 m apf) of the Datong River (Fig. 5).

The sediments are well exposed over $\sim 6 \mathrm{~m}$ depth in road cut, and situated below the surface of the moraine that was formed during the last glaciation according to Kang et al. (1992). The series is composed of four sedimentary units (Fig. 4b, c). The first unit, at 0-0.5 m depth, is the present black soil layer. The second unit, at a depth of $0.5-2.8 \mathrm{~m}$, is a gray diamicton. It consists mainly of very poorly sorted, matrix-supported, disorganized, ungraded, sub-angular to angular gravel (3-20 cm diameter), interfingering with few layers of sand and silt. It contains a few big cobbles ( $>60 \mathrm{~cm}$ diameter), some of which are glacially striated. Therefore, this layer is interpreted to be a till. The third unit, at 2.8-3.7 $\mathrm{m}$ depth, is a black-brown sandy soil layer. The fourth unit, at 3.7-6 m depth, consists of gravel with sand lenses. The lower boundary of the latter layer is not exposed. This unit mainly consists of sub-rounded to sub-angular, poorly sorted pebbles $(2-20 \mathrm{~cm}$ diameter) in a sandy matrix, with very crude horizontal stratification, a fining upward structure and occasionally shows clast imbrication. These sedimentary properties suggest that this layer is deposited as bedload and in longitudinal bars by glacio-fluvial systems. Three OSL samples from this sediment sequence (Fig. $4 \mathrm{~b}$ ) were taken for dating.

2. The HC section is located at a terrace $\sim 7 \mathrm{~m}$ above the present floodplain (altitude $3120 \mathrm{~m}$ ) of the tributary Lairitu River (Fig. 6). The surface of this terrace declines gradually to connect with the T4 terrace (21-23 m apf) of the Datong River (Fig. 6).

The section is composed of a fining-upward fluvial sediment series, covered by a black-brown sandy soil; four OSL samples (HC-1 from covering soil, HC-2, 3 and 4 from fluvial sand and silt) were taken from this section (Fig. 7). The fluvial deposits consist of gravel and coarse sand, which are interpreted to be channel deposits deposited under conditions of waning flow by accretion of progressively smaller clasts and overbank fine sand and silt. The fluvial deposits are strongly involuted and subvertical microjoints are commonly present, which probably originated within a perennially frozen sediment (e.g. Mol et al., 1993). The amplitude of these involutions is $>4 \mathrm{~m}$. The involutions include upward pointed and lobate protrusions of gravels into fine sands and silts, and downward protrusions of sands and silts into gravels. Elongate clasts with the long axes nearly vertical in the gravel layer and fine vertical laminations in sand and silt layer commonly occur (Fig. 7). By analogy to similar structures (e.g. Vandenberghe, 1988, 1992), the involutions of this size are interpreted as structures that are due to periglacial deformation in degrading permafrost (type 2 cryoturbations).

3. Near the Dazuang (DZ) section, four fluvial terraces (T1, T4, T5 and T6) of the Datong River and one moraine ridge occur (Fig. 8). The surface of the ridge declines gradually, and connects with an outwash plain at a sharp slope change. The outwash plain declines gradually to connect with terrace T6 (80 $\mathrm{m}$ apf of the Datong River) (Fig. 8). The ridge is mainly composed of diamicton gravels and sands with similar sedimentary structure as in the second unit of the GSK section which is interpreted to be a till. Below this moraine, the section consists of poorly sorted, ungraded, occasionally imbricated, sub-angular to sub-rounded gravels (5-10 cm diameter). Interfingering sand layers occasionly occur. These sediment properties are in agreement with a glacio-fluvial origin similar to the fourth unit of the GSK section. Thick floodloams $(3.2 \mathrm{~m})$ with silt and brown soil layers were deposited on the sixth terrace (T6), covered by $34 \mathrm{~m}$ loess; sediments were sampled for OSL-dating from the loess (DZ-1) and from the floodloams (3 samples) (Fig. 8).

\section{Dating results}

From all samples, a small but sufficient amount of very fine-sand quartz could be extracted to permit standard SAR-OSL analysis. The dose response can be well represented by either a single saturating exponential or the sum of a single saturating exponential and a linear component (Fig. 9). In general, sensitivity changes occurring during the measurement procedure were accurately corrected for (as indicated by recycling ratios within the range $0.90-1.10$ ) and the growth curves pass very close to the origin (recuperation values well below $1 \%$ of the corrected natural OSL signal). Of 163 large aliquots measured in total, ten were rejected on account of a recycling ratio and three on account of an OSL IR depletion ratio $>10 \%$ from unity. For most samples, an acceptable-to-good dose recovery was achieved (Table 1; measured to given dose ratios within 10\% from unity); it may not be possible to measure given doses in excess of a few hundred Gy with the same degree of accuracy (Table 1, dose recovery data for samples DZ-23 and DZ-28). The average large aliquot quartz doses are summarized in Table 1.

The results of the measurements using small aliquots of samples GSK-1 and -2 are shown as histograms in Fig. 10(a-b). The small amount of quartz available limited the analysis to 30 small aliquots for each sample; six aliquots of sample GSK-1 and 14 aliquots of sample GSK-3 were rejected on account of a recycling ratio or an OSL IR depletion ratio not within $10 \%$ from unity. The distributions are broad, with relative standard deviations in the range of $\sim 16$ to $26 \%$, and display little asymmetry. The unweighted average $\mathrm{D}_{\mathrm{e}}$ 's are somewhat lower than the values obtained using large aliquots (Table 1 ), but it cannot be excluded that this relates to the limited number of small-aliquots. Broad distributions, showing little or no asymmetry, have previously been reported for well-bleached samples (see e.g. Buylaert et al., 2009; Derese et al., 2009; Vandenberghe et al., 2009); the distributions observed for samples GSK-1 and -2 are thus not incompatible with a well-bleached nature.

Table 1 summarizes the analytical data and OSL ages. The uncertainties on the OSL ages were calculated following the error assessment system proposed by Aitken and Alldred (1972) and Aitken (1976). As the ages were obtained using large aliquots, they should at least in 

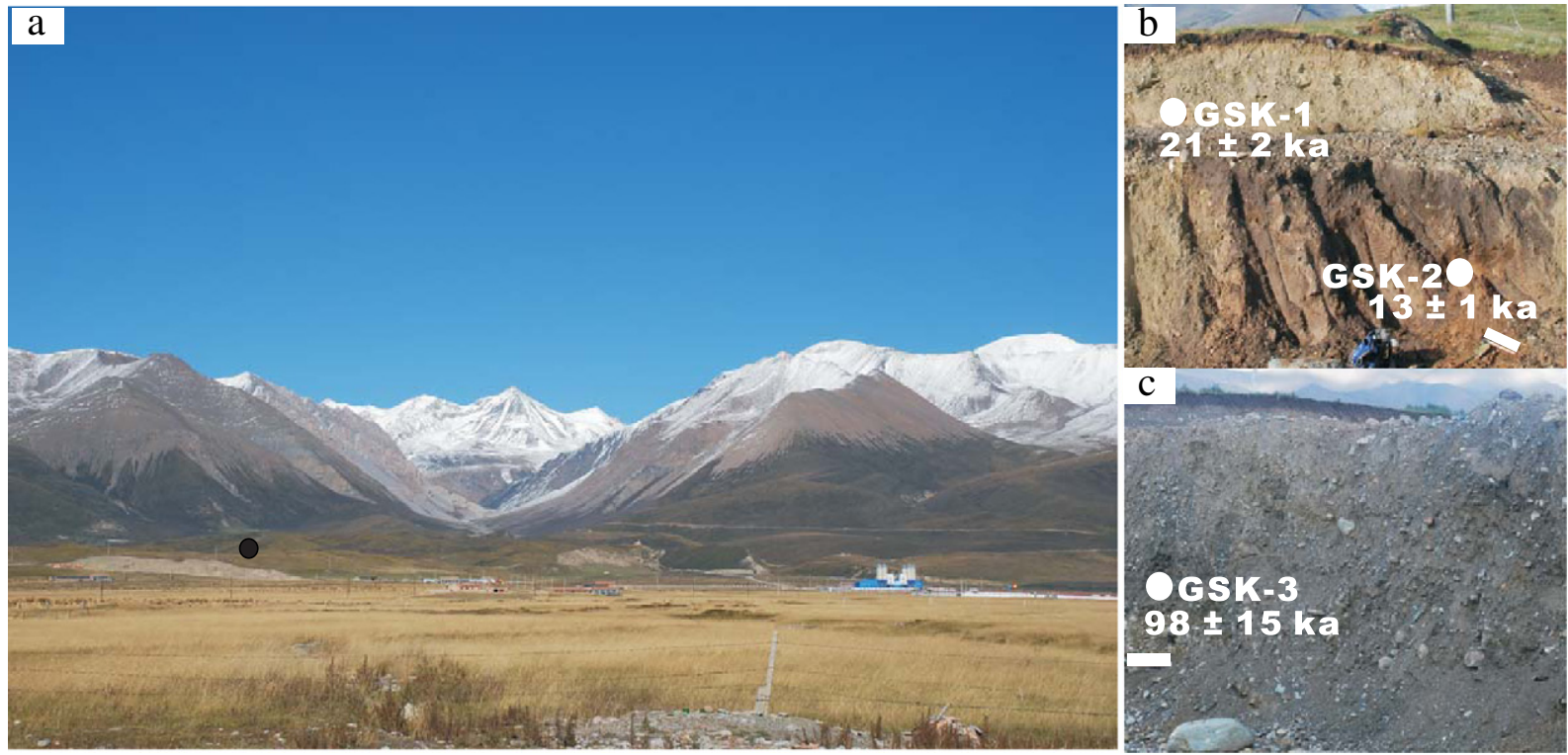

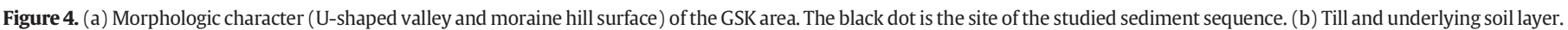

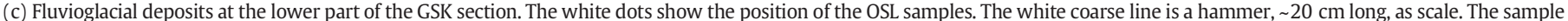
sites for GSK-1 and GSK-2 are 4 m horizontal distance.

principle be considered as maximum ages. The dose distributions, although based on a small number of observations, do not hint incomplete resetting as a significant source of error, however. Also, it has been argued (see e.g. Murray and Olley, 2002; Jain et al., 2003) that incomplete resetting is unlikely to give rise to significant age overestimations for samples older than a few ka, even in glacio-fluvial environments. Thus, like common practice, the mean equivalent doses (ED) and associated standard error were used to estimate the paleodose.

The OSL ages are generally consistent with the stratigraphic position of the samples, except at the GSK section. From top to bottom the deposit sequence is composed of a till on top of glacio-fluvial sediments, separated by a palaeosol at the GSK section (Fig. 4b, c). This sequence may represent a glacial-interglacial-glacial cycle. The sample GSK-1 from the till is dated at $\sim 20 \mathrm{ka}$, indicating a glacial advance during the LGM. In accordance with this result, the underlying soil could be of last interglacial age and the underlying glacio-fluvial sediments could date from the penultimate glaciation. However the OSL dating for GSK-2 is around $13 \mathrm{ka}$.

These two OSL-dates (GSK-1 and GSK-2) are difficult to reconcile on the basis of physical arguments. Nevertheless, we are inclined to accept the $21 \mathrm{ka}$ date for two reasons. First, the age of sample GSK-1 is consistent with the field deposit sequence (last glacial) and ${ }^{14} \mathrm{C}$ ages, reported by Guo et al. (1995), in which one sample of disseminated organic carbon was dated at $\sim 25{ }^{14} \mathrm{C}$ ka BP and one sample using inorganic carbon from calcium carbonate from sandy silt was dated at $31{ }^{14} \mathrm{C}$ ka BP. Second, this moraine occurs at the most exterior position of the nested moraines downstream in the glacial valley, coinciding with the largest extent of the glacier. Usually this position is reached near the maximum of the glacial period. In contrast, the tills deposited at $\sim 13 \mathrm{ka}$ (well after the LGM, 19-23 ka) usually occur in a much more interior position in the glacial valley in many regions in the Tibetan Plateau (e.g. Lehmkuhl and Owen, 2005; Liu et al., 2006; Kong et al., 2009; Zhou et al., 2010). Therefore, although we have no real physical argument to reject the dating of sample GSK-2 (13 ka), we favour the age of GSK-1 ( $21 \mathrm{ka}$ ) because it fits better in the context of a general glacial evolution and the published ${ }^{14} \mathrm{C}$ ages. Further work is needed to clearly resolve the discrepancy.

The dating result of sample GSK-3 seems to be somewhat underestimated when considering that it was collected from a body of sediment underlying the last-interglacial soil. It has been shown that OSL ages derived from the high-dose region of the dose response curve can be inaccurate, with $D_{\mathrm{e}} \mathrm{s}$ being underestimated from about 150-200 Gy onwards (e.g. Murray and Funder, 2003; Buylaert et al., 2007). For the same reason, the results of the samples from the T6

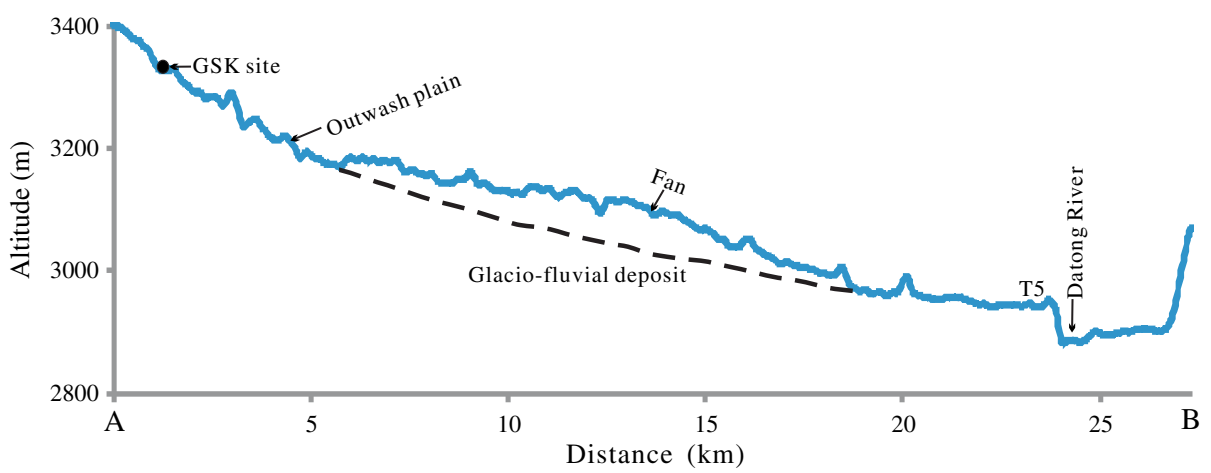

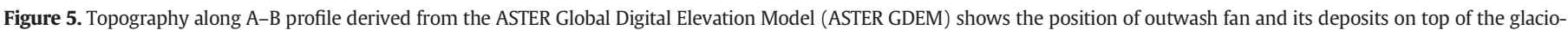
fluvial deposits. The profile shows also the connection between the glaciofluvial deposits and terrace T5. 


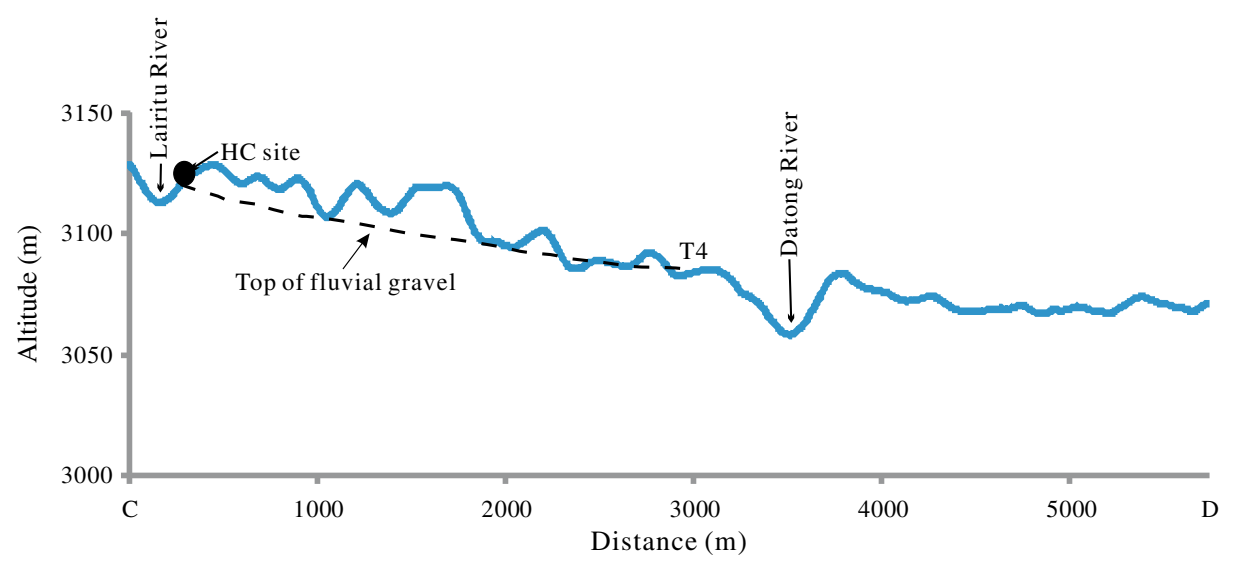

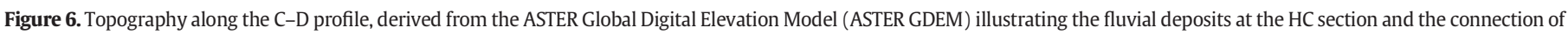
these deposits with the T4 terrace of the Datong River.

terrace at the DZ section should also be interpreted with caution. In any case, these OSL ages demonstrate that these samples are quite old. Since these samples were taken from the loess and floodloam overlying the fluvial gravel deposits, it indicates that the Datong River could have aggraded already before the penultimate glacial (Table 2). The sample (QSZ-1) from floodloam on top of the T3 terrace is dated at around $11 \mathrm{ka}$, indicating that the Datong River possibly also aggraded during the Younger Dryas stadial. Three samples (HC-2, -3 and -4) from fluvial sands involuted in the fluvial gravel which correlates to Datong terrace T4 are dated at around 20-25 ka. This may point to fluvial aggradation of the Datong River during the LGM. Thus, these OSL dating results at three sections are generally consistent with their geomorphologic position (see the correlation of the terrace sequence as summarized in Table 2).

\section{Discussion}

\section{Morphological response to climate conditions}

Based on our OSL results and their interpretation, we conclude that a moraine was constructed at $\sim 21 \mathrm{ka}$, indicating a considerable glacial advance during the LGM in the Qilian Mountains, and possibly correlating to LGM glaciations on the Tibetan Plateau itself (Lehmkuhl and Haselein, 2000). Any MIS 3 advance in the Qilian Mountains must have been smaller than the LGM advance. This chronology differs from that of the southern Tibetan Plateau as established by Owen et al. (2008) in that there the LGM advances were smaller than the MIS 3 advances.
A glacial advance during the MIS3 when Asian monsoon enhanced in the southern Tibetan Plateau has been considered as the response to changes in insolation-controlled monsoon precipitation (Owen et al., 2008; Owen, 2009). But glaciers advanced extensively in the southern Qilian Mountains at $21 \mathrm{ka}$, at the same time as in the northern hemisphere including the eastern Tibetan Plateau, reaching their maximum extent since the late Pleistocene (Ou et al., 2012). This would suggest that the factor controlling glaciation in the Qilian Mountains is similar to that in the eastern Tibetan Plateau. It means that the general temperature decline in the Northern Hemisphere during MIS-2 seems to have been more important than any precipitation increase during MIS-3 in causing glaciers to grow (Ou et al., 2012). However, this conclusion remains to be confirmed through additional absolute dating of tills that belong to the maximum glacier extent.

Fluvial sediments deposited during LGM at the HC section (T3) and penultimate glacial at the GSK section (T5) indicate that fluvial aggradation in the Menyuan basin occurred mainly during cold periods. This link between fluvial deposition and cold environment might also be supported by the aggradation of T4 that occurred at $\sim 11 \pm 1 \mathrm{ka}$, perhaps during the Younger Dryas. Because this is based on a single age with associated uncertainty, this last conclusion is not definitive. Besides, paleo-precipitation conditions in the northeastern Tibetan Plateau during the Younger Dryas are not well known (Zhou et al., 2001; Shen et al., 2005).

The aggradation of the younger terraces (T1 and T2) during the Holocene is exceptional and could be affected by intrinsic-dynamic evolution or tectonic activity as no strong climate fluctions occured during the Holocene. The relationship between fluvial activity and climatic
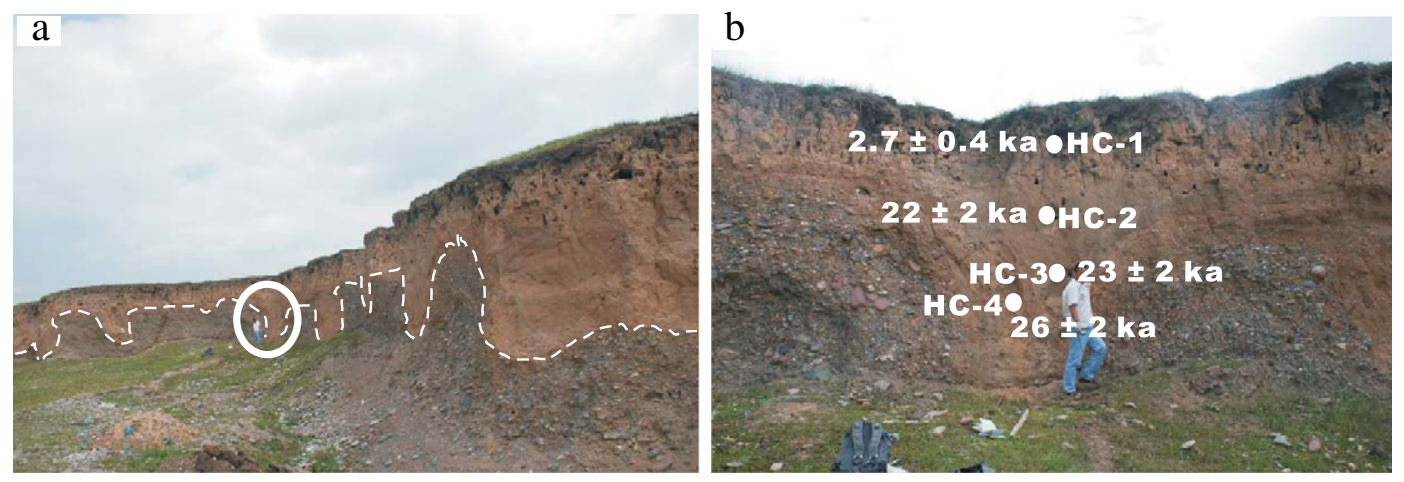

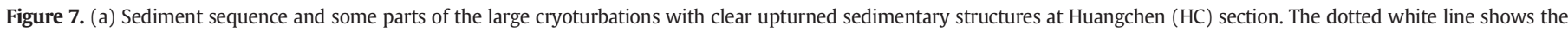

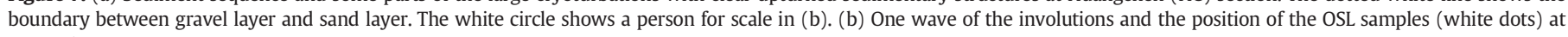
HC section. 


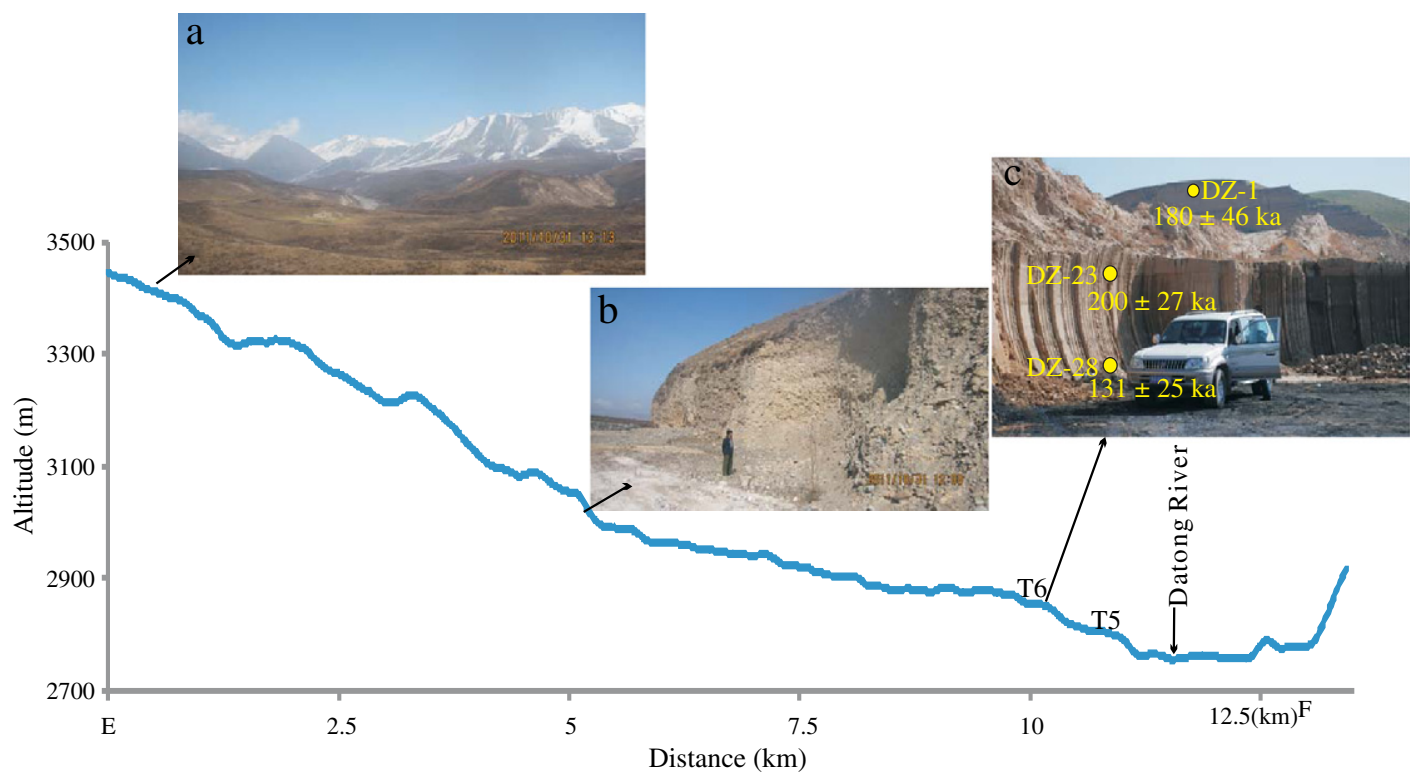

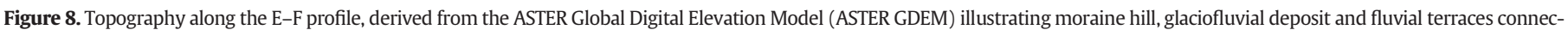

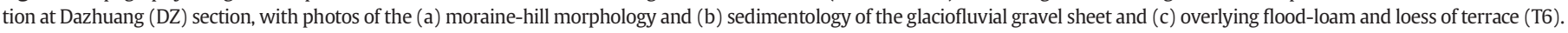
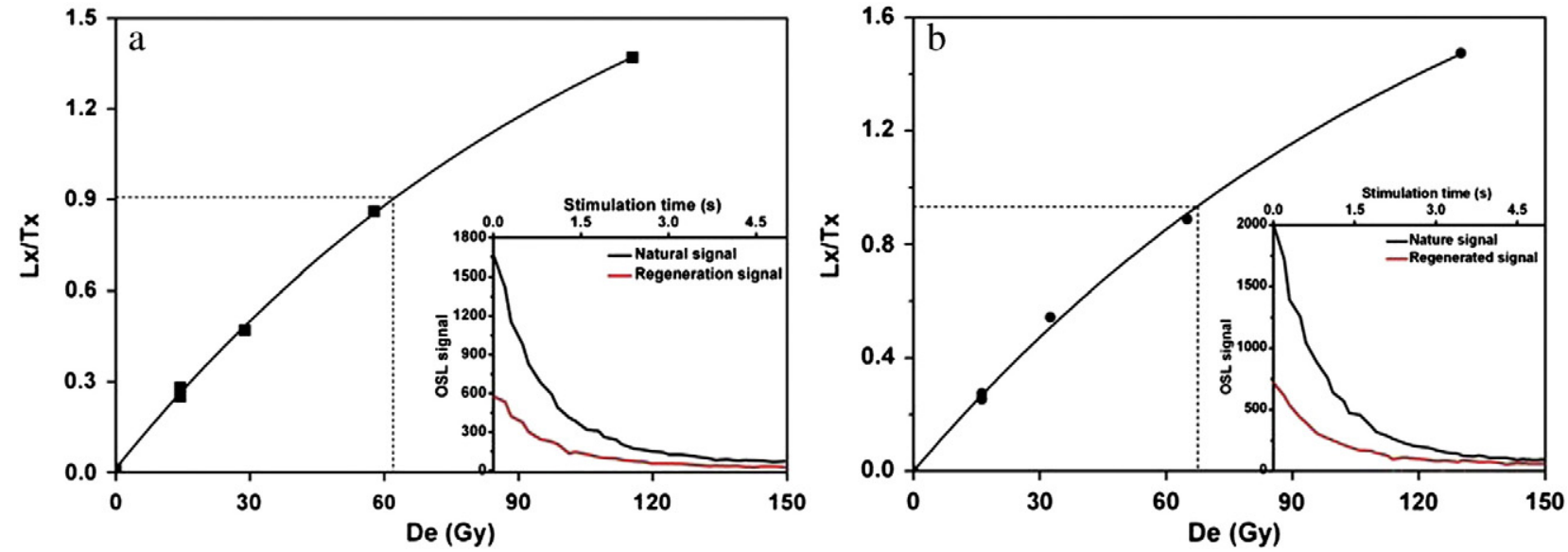

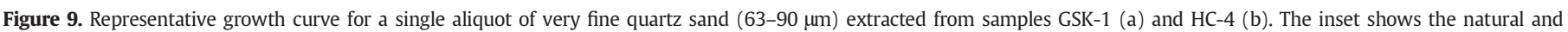
regenerated OSL decay curves.

conditions is similar to results from other regions as summarized by Vandenberghe (1995, 2002) and Bridgland and Westaway (2008). In contrast, on the southern Himalayan front, it has been argued that relatively high precipitation caused river aggradation during MIS 3 and 2 since the ITCZ migration to somewhere on the lower heights of the Lesser Himalayan zone should have induced strong precipitation

Table 1

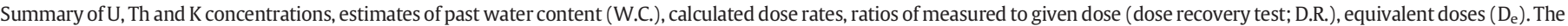

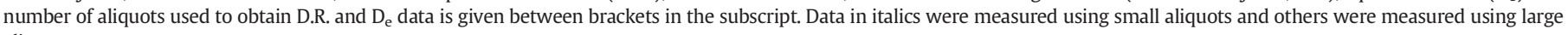
aliquots.

\begin{tabular}{|c|c|c|c|c|c|c|c|c|c|c|}
\hline Sample lab-code & Sample field-code & $\begin{array}{l}\text { Depth } \\
(\mathrm{cm})\end{array}$ & $\begin{array}{l}\mathrm{U} \\
(\mathrm{ppm})\end{array}$ & $\begin{array}{l}\text { Th } \\
(\mathrm{ppm})\end{array}$ & $\begin{array}{l}\mathrm{K} \\
(\%)\end{array}$ & $\begin{array}{l}\text { W.C. } \\
(\%)\end{array}$ & $\begin{array}{l}\text { Dose rate } \\
\left(\mathrm{Gy} \mathrm{ka}^{-1}\right)\end{array}$ & D.R. & $\begin{array}{l}D_{e} \\
(G y)\end{array}$ & $\begin{array}{l}\text { Age } \\
(\mathrm{ka})\end{array}$ \\
\hline NJU-719 & $\mathrm{HC}-1$ & 80 & $2.26 \pm 0.04$ & $12.80 \pm 0.03$ & $2.08 \pm 0.03$ & $25 \pm 6$ & $2.99 \pm 0.02$ & $1.04 \pm 0.03_{(6)}$ & $8.0 \pm 0.2_{(24)}$ & $2.70 \pm 0.4$ \\
\hline NJU-720 & HC-2 & 230 & $1.91 \pm 0.04$ & $8.24 \pm 0.03$ & $1.71 \pm 0.03$ & $15 \pm 4$ & $2.55 \pm 0.03$ & $1.09 \pm 0.02_{(6)}$ & $55 \pm 1_{(18)}$ & $22 \pm 2$ \\
\hline NJU-721 & $\mathrm{HC}-3$ & 320 & $1.72 \pm 0.05$ & $7.25 \pm 0.03$ & $1.60 \pm 0.03$ & $12 \pm 3$ & $2.39 \pm 0.03$ & $1.06 \pm 0.02_{(6)}$ & $55 \pm 2_{(17)}$ & $23 \pm 2$ \\
\hline NJU-722 & $\mathrm{HC}-4$ & 430 & $1.92 \pm 0.04$ & $8.54 \pm 0.03$ & $1.63 \pm 0.03$ & $12 \pm 3$ & $2.52 \pm 0.03$ & $1.16 \pm 0.09_{(6)}$ & $67 \pm 1_{(22)}$ & $26 \pm 2$ \\
\hline NJU-723 & QSZ-1 & 110 & $3.20 \pm 0.04$ & $11.90 \pm 0.03$ & $1.70 \pm 0.03$ & $18 \pm 5$ & $2.97 \pm 0.03$ & $0.95 \pm 0.05_{(6)}$ & $34 \pm 2_{(17)}$ & $11 \pm 1$ \\
\hline NJU-588 & GSK-1 & 250 & $2.78 \pm 0.04$ & $12.80 \pm 0.03$ & $2.03 \pm 0.03$ & $13 \pm 3$ & $3.33 \pm 0.02$ & $1.00 \pm 0.06_{(6)}$ & $69 \pm 3_{(19)}$ & $21 \pm 2$ \\
\hline NJU-589 & GSK-2 & 350 & $3.06 \pm 0.04$ & $12.50 \pm 0.03$ & $1.92 \pm 0.03$ & $15 \pm 4$ & $3.19 \pm 0.02$ & $0.99 \pm 0.04_{(6)}$ & $40 \pm 1_{(16)}$ & $13 \pm 1$ \\
\hline NJU-590 & GSK-3 & 450 & $2.35 \pm 0.05$ & $12.10 \pm 0.03$ & $2.19 \pm 0.02$ & $12 \pm 3$ & $3.29 \pm 0.02$ & $0.88 \pm 0.07_{(6)}$ & $321 \pm 42_{(8)}$ & $98 \pm 15$ \\
\hline NJU-699 & DZ-1 & 70 & $2.36 \pm 0.04$ & $10.80 \pm 0.04$ & $1.86 \pm 0.03$ & $15 \pm 4$ & $2.96 \pm 0.03$ & $0.97 \pm 0.10_{(3)}$ & $533 \pm 127_{(3)}$ & $180 \pm 46$ \\
\hline NJU-710 & DZ-23 & 2570 & $2.86 \pm 0.04$ & $12.60 \pm 0.03$ & $2.02 \pm 0.03$ & $15 \pm 4$ & $3.03 \pm 0.03$ & $1.40 \pm 0.12_{(3)}$ & $604 \pm 48_{(3)}$ & $200 \pm 27$ \\
\hline NJU-713 & DZ-28 & 2800 & $3.09 \pm 0.04$ & $11.80 \pm 0.03$ & $1.93 \pm 0.03$ & $15 \pm 4$ & $2.95 \pm 0.03$ & $1.40 \pm 0.06_{(3)}$ & $387 \pm 60_{(3)}$ & $131 \pm 25$ \\
\hline NJU-588* & GSK-1 & 250 & $2.78 \pm 0.04$ & $12.80 \pm 0.03$ & $2.03 \pm 0.03$ & $13 \pm 3$ & $3.33 \pm 0.02$ & & $62 \pm 3_{(24)}$ & $19 \pm 1$ \\
\hline NJU-589※ & GSK-2 & 350 & $3.06 \pm 0.04$ & $12.50 \pm 0.03$ & $1.92 \pm 0.03$ & $15 \pm 4$ & $3.19 \pm 0.02$ & & $34 \pm 2_{(16)}$ & $11 \pm 1$ \\
\hline
\end{tabular}



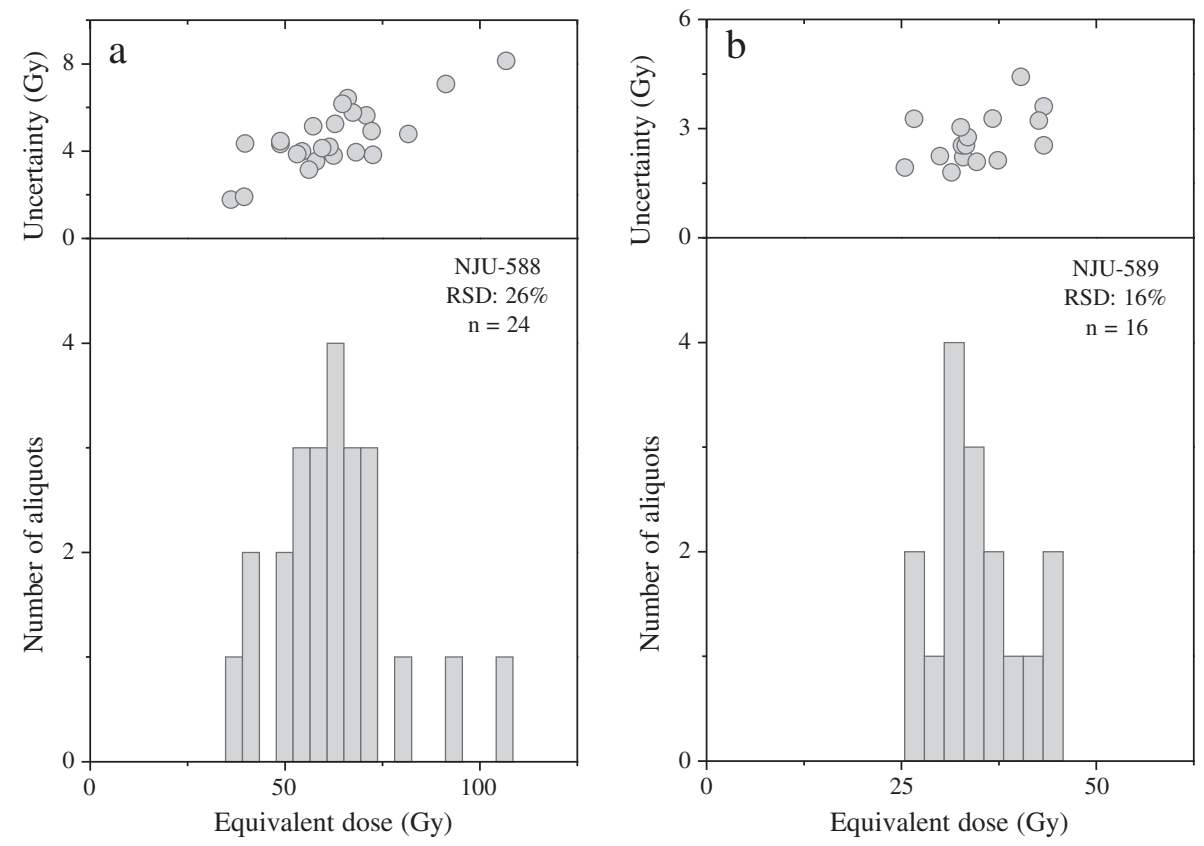

Figure 10. Histogram of $D_{e}$ distribution: (a) for GSK-1 and (b) for GSK-2 using small aliquots.

there even during the LGM (Ray and Srivastava, 2010). Prell and Kutzbach (1987) modeled rainfall over the Indian subcontinent during the LGM and found that precipitation was reduced to 70\% of presentday values, yet even that lowered amount is thought to have been enough to mobilize sediment and cause aggradation in the valleys (Srivastava et al., 2008; Ray and Srivastava, 2010). Precipitation (in the form of snow) might also have been sufficient during cold periods in the northeastern Tibetan Plateau (Yang and Scuderi, 2010) to affect the fluvial aggradation in the Qilian Mountains, as in the southern Himalayas, especially during the summer with large amounts of meltwater. We conclude that fluvial aggradation took place in the Menuyan basin especially during cold climates.

\section{Paleoenvironmental reconstruction}

At the GSK section the sequence consists of a moraine, a soil (of interglacial type), and glacio-fluvial sheet deposits (sandrs). This sequence probably reflects a temporal evolution from cold and probably moist conditions during the penultimate glaciation, to warm and wet climate during the last interglaciation, and finally to very cold climate with a glacial advance during the LGM. In addition, the fluvial sediment with very large cryoturbation structures around 24-21 ka pointed to the presence of continuous permafrost during the LGM, supporting the opinion that at elevations higher than $1200 \mathrm{~m}$ the southern limit of continuous permafrost occurred south of $38^{\circ} \mathrm{N}$ then (Vandenberghe et al., 2004). By analogy to similar structures in coarse-grained deposits, the involutions of this size were interpreted as type 2 cryoturbations, indicating a mean annual temperature of maximum $-8{ }^{\circ} \mathrm{C}$ (e.g. Vandenberghe, 1988, 1992, 1993) during the LGM. Based on these estimates, the mean annual temperature difference between the LGM and now could be estimated to be at least $7.2{ }^{\circ} \mathrm{C}$ in the Menyuan basin. This was consistent with the early view that the temperature was $6-9{ }^{\circ} \mathrm{C}$ lower during the LGM than at present in the Tibetan Plateau as derived from changes of the snowline (Shi, 2002, and references in there). Although this temperature difference was smaller than $13{ }^{\circ} \mathrm{C}$ as reconstructed from sand wedges in adjacent regions (Wang et al., 2001; Vandenberghe et al., 2004), the value of $7.2{ }^{\circ} \mathrm{C}$ was only a minimum value which is in any case much higher than the $2.8^{\circ} \mathrm{C}$ difference assumed at the Qinghai Lake by Porter et al. (2001). The presence of cryoturbations and absence of sand wedges in the Menyuan basin contrasted with the general presence of sand-wedges and absence of cryoturbations in adjacent regions (Wang et al., 2003; Vandenberghe et al., 2004). This indicated that it was more humid in the Menyuan basin than in adjacent regions such as the Mu Us desert and Hexi Corridor during the LGM.

\section{Conclusions}

Quartz-based SAR-OSL analysis yielded ages that are generally consistent with the stratigraphic and geomorphological position of the samples. The results demonstrate that the method could provide robust age control for glacial and fluvial deposits in the Menyuan basin in the

Table 2

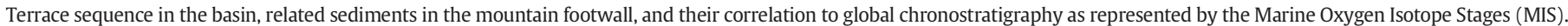

\begin{tabular}{|c|c|c|c|c|c|}
\hline \multicolumn{2}{|c|}{ Terrace in the basin } & \multicolumn{3}{|c|}{ Sediments near mountain } & \multirow[t]{2}{*}{ Stage } \\
\hline Sequence & Altitude (m) & GSK & $\mathrm{HC}$ & HTS & \\
\hline- & & Soil & Soil & & MIS 1 \\
\hline T3 & +14 & & & & Younger Dryas \\
\hline $\mathrm{T} 4$ & $+21-23$ & Till & Involuted fluvial sands & Till? & MIS 2 \\
\hline- & & Soil? & & & MIS 5? \\
\hline T5 & $+44-46$ & Glacio-fluvial gravel and sands & & & MIS 6 \\
\hline $\mathrm{T} 6$ & +80 & & & Glacio-fluvial gravel and sands & $>$ MIS 6 \\
\hline
\end{tabular}


northeastern Tibetan Plateau, which can be a vital solution for the lack of suitable materials for radiocarbon and terrestrial cosmogenic nuclide exposure dating in this region.

Although further work at more localities is required, our finds suggest that glaciers advanced during LGM, indicating that the temperature decline was the critical factor for glacial fluctuations in this region as in the eastern Tibetan Plateau, rather than monsoon-related precipitation. Because fluvial aggradation occurred during the penultimate glacial, the LGM and the Younger Dryas, as the general terrace formation model in temperate and cold regions (last modified by Vandenberghe, 2008), the increase of sediment supply in periglacial conditions was the main factor controlling fluvial aggradation in the Menyuan basin, rather than any monsoon-related precipitation increase. Periglacial structures in the Menyuan basin show that the mean annual temperature was $>7{ }^{\circ} \mathrm{C}$ lower during the LGM than at present and that conditions there were more humid than in adjacent regions. Extensive quartz-based SAR-OSL datings of till, fluvial and fluvio-glacial deposits in the Tibetan Plateau where it is sensitive to global climate could provide vital clues to unravel the detail relationship between earth surface processes (glacial fluctuations, fluvial erosion and deposition) and climate changes.

\section{Acknowledgments}

This research was supported by the National Natural Science Foundation of China (grant nos. 41271001, 40901002 and 41230526 ), Ph.D. Programs Foundation of Ministry of Education of China (20090091120032), and the Dutch-Chinese CAS-KNAW PhD Project (05-PhD-10) and Exchange Programs (08CDP028, 09CDP033 and 10CDP036). Prof. Pan Baotian and Prof. Yang Dayuan are thanked for constructive discussions. Miss. Zhai Min, Mr. Zhang Wenchao, Mr. Yang Chuanbin and Dr. Stefan Vasiliniuc are thanked for field and laboratory assistance. DV is a Postdoctoral Fellow of the Research Foundation Flanders (FWO-Vlaanderen). The comments by Prof. Alan R. Gillespie and Prof. Lai Zhongping and two anonymous reviewers are highly appreciated.

\section{References}

Adamiec, G., Aitken, M.J., 1998. Dose-rate conversion factors: new data. Ancient TL 16, 37-50.

Aitken, M.J., Alldred, J.C., 1972. The assessment of error limits in thermo-luminescence dating. Archaeometry 14, 257-267.

Aitken, M.J., 1976. Thermoluminescent age evaluation and assessment of error limits: revised system. Archaeometry 18, 233-238.

Benn, D.I., Owen, L.A., 1998. The role of the Indian summer monsoon and the mid-latitude westerlies in Himalayan glaciation: review and speculative discussion. Journal of the Geological Society 155, 353-363.

Bridgland, D.R., Westaway, R., 2008. Preservation patterns of Late Cenozoic fluvial deposits and their implications: results from IGCP 449. Quaternary International 189, 5-38.

Buylaert, J.-P., Vandenberghe, D., Murray, A.S., Huot, S., De Corte, F., Van den haute, P., 2007. Luminescence dating of old (>70 ka) Chinese loess: a comparison of singlealiquot OSL and IRSL techniques. Quaternary Geochronology 2, 9-14.

Buylaert, J.-P., Ghysels, G., Murray, A.S., Thomsen, K.J., Vandenberghe, D., De Corte, F., Heyse, I., Van den haute, P., 2009. Optical dating of relict sand wedges and composite-wedge pseudomorphs in Flanders, Belgium. Boreas 38, 160-175.

Bøtter-Jensen, L., Andersen, C.E., Duller, G.A.T., Murray, A.S., 2003. Developments in radiation, stimulation and observation facilities in luminescence measurements. Radiation Measurements 37, 535-541.

Derbyshire, E., 1987. A history of the glacial stratigraphy in China. Quaternary Science Reviews 6, 301-314

Derese, C., Vandenberghe, D., Paulissen, E., Van den haute, P., 2009. Revisiting a type locality for Late Glacial aeolian sand deposition in NW Europe: optical dating of the dune complex at Opgrimbie (NE Belgium). Geomorphology 109, 27-35.

Duller, G.A.T., 2003. Distinguishing quartz and feldspar in single grain luminescence measurements. Radiation Measurements 37, 161-165.

Dutta, S., Suresh, N., Kumar, R., 2012. Climatically controlled Late Quaternary terrace staircase development in the fold-and-thrust belt of the Sub Himalaya. Palaeogeography, Palaeoclimatology, Palaeoecology 356-357, 16-26.

Gibling, M.R., Tandon, S.K., Sinha, R., Jain, M., 2005. Discontinuity bounded alluvial sequences of the southern Gangetic plains, India: aggradation and degradation in response to monsoonal strength. Journal of Sedimentary Research 75, 369-385.

Goodbred Jr., S.L., 2003. Response of Ganges dispersal system to climatic change: a source to sink view since the last interstade. Sedimentary Geology 162, 83-104.
Guo, H., Chen, Y., Li, J., 1995. A preliminary study on the sequences of glaciers, loess records and terraces of the southern foothills of Lenlong Ling in Qilian Mountains. Journal of Lanzhou University (Natural Sciences) 31 (1), 102-110 (in Chinese with English abstract)

Jain, M., Murray, A.S., Bøtter-Jensen, L., 2003. Optically stimulated luminescence dating: how significant is incomplete light exposure in fluvial environments? Quaternaire 15, 143-157.

Kang, J., Zhu, J., Chen, H., 1992. Late Quaternary glacial sequence on the south slope of the Lenglongling, Qilian Mountains. Journal of Glaciology and Geocryology 14 (4), 352-359 (in Chinese with English abstract).

Kong, P., Fink, D., Na, C., Huan, F., 2009. Late Quaternary glaciation of the Tianshan, Central Asia, using cosmogenic ${ }^{10} \mathrm{Be}$ surface exposure dating. Ouaternary Research 72, 229-233.

Lai, Z., Kaiser, K., Brückner, H., 2009. Luminescence-dated aeolian deposits of late Quaternary age in the southern Tibetan Plateau and their implications for landscape history. Quaternary Research 72, 421-430.

Lehmkuhl, F., Haselein, F., 2000. Quaternary paleoenvironmental change on the Tibetan Plateau and adjacent areas (Western China and Western Mongolia). Quaternary International 65 (66), 121-145.

Lehmkuhl, F., Owen, L.A., 2005. Late Quaternary glaciation of Tibet and the bordering mountains: a review. Boreas 34, 87-90.

Liu, G., Zhang, X., Cui, Z., Wu, Y., Ju, Y., 2006. A review of glacial sequences of the Kunlun Pass, northern Tibetan Plateau. Quaternary International 154-155, 63-72.

Liu, X.D., Chen, B.D., 2000. Climatic warming in the Tibetan Plateau during the recent decades. International Journal of Climatology 20, 1729-1742.

Liu, X., Lai, Z., Fan, Q., Long, H., Sun, Y., 2010. Timing for high lake levels of Qinghai Lake in the Qinghai-Tibetan Plateau since the Last Interglaciation based on quartz OSL dating. Quaternary Geochronology 5, 218-222.

Liu, X.J., Lai, Z.P., 2013. Optical dating of sand wedges and ice-wedge casts from Qinghai Lake area on the northeastern Qinghai-Tibetan Plateau and its palaeoenvironmental implications. Boreas 42, 333-341.

Long, H., Lai, Z., Wang, N., Zhang, J., 2011. A combined luminescence and radiocarbon dating study of Holocene lacustrine sediments from arid northern China. Quaternary Geochronology 6, 1-9.

Lu, H.Y., Wang, X.Y., An, Z., Miao, X., Zhu, R., Ma, H., Li, Z., Tan, H., Wang, X., 2004. Geomorphologic evidence of phased uplift of the northeastern Qinghai-Tibet Plateau since 14 million years ago. Science in China Series D 47 (9), 822-833.

Lu, H.Y., Zhao, C., Mason, J., Yi, S.W., Zhao, H., Zhou, Y., Ji, J., Swinehart, J., Wang, C., 2011. Holocene climatic changes revealed by aeolian deposits from the Qinghai Lake area (northeastern Qinghai-Tibetan Plateau) and possible forcing mechanisms. The Holocene 21, 297-304.

Mejdahl, V., 1979. Thermoluminescence dating: beta attenuation in quartz grains. Archaeometry 21, 61-73.

Miall, A., 1996. The Geology of Fluvial Deposits. Springer, Berlin (582 pp.).

Mol, J., Vandenberghe, J., Kasse, C., Stel, H., 1993. Periglacial microjointing and faulting in Weichselian fluvi-aeolian deposits. Journal of Quaternary Science 8, 15-30.

Murray, A.S., Funder, S., 2003. Optically stimulated luminescence dating of a Danish Eemian coastal marine deposit: a test of accuracy. Quaternary Science Reviews 22, 1177-1183.

Murray, A.S., Olley, J.M., 2002. Precision and accuracy in the optically stimulated luminescence dating of sedimentary quartz: a status review. Geochronometria 21, 1-16.

Murray, A.S., Wintle, A.G., 2000. Luminescence dating of quartz using an improved singlealiquot regenerative-dose protocol. Radiation Measurements 32, 57-73.

Murray, A.S., Wintle, A.G., 2003. The single aliquot regenerative dose protocol: potential for improvements in reliability. Radiation Measurements 37, 377-381.

Ou, X.J., Lai, Z.P., Zeng, L.H., Zhou, S.Z., 2012. OSL dating of glacial sediments from the Qinghai-Tibetan Plateau and its bordering mountains: a review and methodological suggestions. Journal of Earth Environment 3 (2), 829-842.

Owen, L.A., 2009. Latest Pleistocene and Holocene glacier fluctuations in the Himalaya and Tibet. Quaternary Science Reviews 28, 2150-2164.

Owen, L.A., Caffee, M.W., Finkel, R.C., Seong, B.S., 2008. Quaternary glaciation of the Himalayan-Tibetan orogen. Journal of Quaternary Science 23, 513-532.

Pan, B.T., Li, J.J., Chen, F.H., 1995. The Qinghai-Tibetan Plateau: Driver and amplfier of the global climatic changes. I The characteristics of climatic changes in Cenozoic. Journal of Lanznhou University (Natural Science Edition) 31, 120-128 (in Chinese).

Pan, B., Su, H., Hu, Z., Hu, X., Gao, H., Guan, Q., Li, J.J., Kirby, E., 2009. Evaluating the role of climate and tectonics during non-steady incision of the Yellow river: evidence from a 1.24 Ma terrace record near Lanzhou, China. Quaternary Science Reviews $28,3281-3290$

Porter, S.C., Singhvi, A., An, Z.S., Lai, Z.P., 2001. Luminescence age and palaeoenvironmental implications of a Late-Pleistocene ground wedge on the Northeastern Tibetan Plateau. Permafrost and Periglacial Processes 12, 203-210.

Prescott, J.R., Hutton, J.T., 1994. Cosmic ray contributions to dose rates for luminescence and ESR dating: large depths and long-term time variations. Radiation Measurements 23, 497-500

Ray, Y., Srivastava, P., 2010. Widespread aggradation in the mountainous catchment of the Alaknanda-Ganga River System: timescales and implications to Hinterland-foreland relationships. Quaternary Science Reviews 29, 2238-2260.

Shen, J., Liu, X., Wang, S., 2005. Palaeoclimatic changes in the Qinghai Lake area during the last 18,000 years. Quaternary International 136, 131-140.

Shi, Y., 2002. Characteristics of late Quaternary monsoonal glaciations on the Tibetan Plateau and in East Asia. Quaternary International 97 (98), 79-91.

Srivastava, P., Tripathi, J.K., Islam, R., Jaiswal, M.K., 2008. Fashion and phases of Late Pleistocene aggradation and incision in Alaknanda River, western Himalaya, India. Quaternary Research 70, 68-80.

Thiede, R.C., Bookhagen, B., Arrowsmith, J.R., Sobel, E.R., Strecker, M.R., 2004 Climatic control on rapid exhumation along the southern Himalayan Front. Earth and Planetary Science Letters 222, 791-806. 
Vandenberghe, D., De Corte, F., Buylaert, J.-P., Kučera, J., Van den haute, P., 2008. On the internal radioactivity in quartz. Radiation Measurements 43, 771-775.

Vandenberghe, D., Vanneste, K., Verbeeck, K., Paulissen, E., Buylaert, J.-P., De Corte, F., Van den haute, P., 2009. Lat Weichselian and Holocene earthquake events along the Geleen fault in NE Belgium: OSL age constraints. Quaternary International 199, 56-74.

Vandenberghe, J., 1988. Cryoturbations. In: Clark, M.J. (Ed.), Advances in Periglacial Geomorphology. John Wiley and Sons, Chichester, pp. 179-198.

Vandenberghe, J., 1992. Cryoturbations: a sediment structural analysis. Permafrost and Periglacial Processes 3, 343-352.

Vandenberghe, J., Cui, Z., Zhao, L., Zhang, W., 2004. Thermal-contraction-crack networks as evidence for Late-Pleistocene. Permafrost in Inner Mongolia, China. Permafrost and Periglacial Processes 15, 21-29.

Vandenberghe, J., 1995. Timescales, climate and river development. Quaternary Science Reviews 14, 631-638.

Vandenberghe, J., 2002. The relation between climate and river processes, landforms and deposits during the Quaternary. Quaternary International 91, 17-23.

Vandenberghe, J., 2003. Climate forcing of fluvial system development: an evolution of ideas. Quaternary Science Reviews 22, 2053-2060.

Vandenberghe, J., 2008. The fluvial cycle at cold-warm-cold transitions in lowland regions: a refinement of theory. Geomorphology 98, 275-284.

Vandenberghe, J., Wang, X.Y., Lu, H.Y., 2011. The impact of differential tectonic movement on fluvial morphology and sedimentology along the northeastern Tibetan Plateau. Geomorphology 134, 171-185.
Wang, N., Zhao, Q., Li, J., Hu, G., Cheng, H., 2003. The sand wedges of the last ice age in the Hexi Corridor, China: paleoclimatic interpretation. Geomorphology 51, 213-320.

Wang, X.Y., Lu, H.Y., Vandenberghe, J., Zheng, S., Van Balen, R.T., 2012. Late Miocene uplift of the NE Tibetan Plateau inferred from basin filling, planation and fluvial terraces in the Huang Shui catchment. Global and Planetary Change 88-89, 10-19.

Yang, X., Scuderi, L., 2010. Hydrological and climatic changes in deserts of China since the late Pleistocene. Quaternary Research 73, 1-9.

Yi, C., Chen, H., Yang, J., Liu, B., Fu, P., Liu, K., Li, S., 2008. Review of Holocene glacial chronologies based on radiocarbon dating in Tibet and its surrounding mountains. Journal of Quaternary Science 23, 533-543.

Zhao, J., Zhou, S., Shi, Z., Ye, Y., Zhang, S., Cui, J., Xu, L., 2001. ESR dating of glacial tills of Baishuihe River on the southern slope of Lenglongling in the eastern part of Qilian Mountain. Journal of Lanzhou University (Natural Sciences) 37 (4), 110-117 (in Chinese with English abstract).

Zhou, S., Li, J., Zhang, S., 2002. Quaternary glaciation of the Bailang River Valley, Qilian Shan. Quaternary International 97 (98), 103-110.

Zhou, S., Wang, J., Xu, L., Wang, X., Patrick, M., David, M., 2010. Glacial advances in southeastern Tibet during late Quaternary and their implications for climatic changes. Quaternary International 218, 58-66.

Zhou, W., Head, M., An, Z., Deckker, P., Liu, Z., Liu, X., Lu, X., Donahue, D., Jull, A., Beck, J., 2001. Terrestrial evidence for a spatial structure of tropical-polar interconnections during the Younger Dryas episode. Earth and Planetary Science Letters 191, 231-239. 